\title{
Concerns about One's Own Future or Securing Child's Future: Paradox of Childbearing Decision Making
}

\author{
Nourossadat Kariman', Masoumeh Simbar ${ }^{2 *}$, Fazlollah Ahmadi' ${ }^{3}$, Abou Ali Vedadhir ${ }^{4}$ \\ ${ }^{1}$ Department of Midwifery and Reproductive Health, Shahid Beheshti University of Medical Science, Tehran, Iran \\ ${ }^{2}$ The Research Center for Safe Motherhood, Department of Midwifery and Reproductive Health, Shahid \\ Beheshti University of Medical Science, Tehran, Iran \\ ${ }^{3}$ Department of Nursing, Faculty of Medical Sciences, Tarbiat Modares University, Tehran, Iran \\ ${ }^{4}$ Department of Antropology, Tehran University, Tehran, Iran \\ Email: ${ }^{*}$ msimbar@sbmu.ac.ir, ${ }^{*}$ msimbar@yahoo.com
}

Received 28 February 2014; revised 3 April 2014; accepted 12 April 2014

Copyright (C) 2014 by authors and Scientific Research Publishing Inc.

This work is licensed under the Creative Commons Attribution International License (CC BY). http://creativecommons.org/licenses/by/4.0/

(c) () Open Access

\begin{abstract}
Background and Purpose: Researchers' incomplete perception of the concerns about childbearing decision making process is revealed in discussions about policies and programs that are designed to influence fertility. Perceiving the concerns of women is essential to explain process of decision making for childbearing. This study aimed to understand women's main concerns about childbearing decision making. Methods: This qualitative study was performed by conventional content analysis approach. The participants included 22 married women in Tehran who were pregnant for the first time or were using contraceptive methods. Purposeful sampling began and continued up to data saturation. To collect data, the unstructured in-depth interviews were used. Data were analyzed using qualitative content analysis by Lundman and Graneheim method. Findings: Four categories were obtained from data including "fear", "uncertainty", "hope" and "financial security". The main category or theme was "concerns about one's own future or securing child's future" that was extracted as the main concern of women about childbearing decision making process. Conclusion: The findings of this study suggest that concerns about one's own future or securing child's future are the main concerns of women about childbearing decision making. Deep understanding of women's concerns about childbearing will help midwives and other service providers to provide services, strategies and more sensitive and appropriate interventions.
\end{abstract}

\section{Keywords}

Concern, Decision Making, Childbearing, Qualitative Study, Content Analysis

${ }^{*}$ Corresponding author. 


\section{Introduction}

Iran has experienced dramatic demographic changes in recent decades. Estimates of fertility trends suggest that the total fertility rate decreased from 7.7 births per woman in 1966 to 1.8 in 2009 [1]-[3]. This decreasing trend continued and the 2011 census reveals that the country's total fertility rate dropped to about 1.7 [4].

Moreover, total fertility rate in 24 out of 30 provinces of Iran has reached below replacement level of 1.2 [5]. Tehran's fertility survey results indicate that sub-replacement fertility level of Tehran (less than 1.5) is mainly due to the deliberate marital fertility control by women in the early and mid-reproductive age [6] [7].

Studies have shown that a change in reproductive behavior is one of the main causes of decline in population growth below the replacement level [8]-[16]. It has been critical for demographers and other scholars to understand fertility behavior and people's decisions made on how and when to bear a child for several decades. However, unlike a lot of attention to this issue, progression to develop a clear understanding of what encourages people to have a child, and processes, concerns during which decisions can be made on fertility are varying at best [17]. Furthermore, childbearing decision making is a complex multilayered process influenced by many factors [18]. In addition, human reproduction has an uncertain process and is not completely a reasonable behavior [19] and the consequence of this decision is unpredictable at least at a personal level [17].

Researchers have investigated and recognized several factors influencing childbearing decision making. Many studies have determined the mother's age as the most important factor and concern predicting fertility and its risks and complications. Childbearing age increase is associated with enhanced risk of infertility [20]. In addition, the most important factors influencing readiness for childbearing are referred to as education, financial security, relationship factors, the suitability of partners and their interest [20] [21].

Moreover, how children are valued, which is itself induced by structure of society, family and couple's psycho-social make-up, affects childbearing decisions and fertility rates. People continue their religion, nationality, values, and traditions through their children and by transferring these to their children preserve their cultural and genetic heritage [22]. Childbearing can have the following advantages: source of income, work force, and looking after parents when aged, ill, or debilitated. Obviously, having children involves costs including: direct maintenance costs, rearing costs and indirect costs associated with lost opportunities while bringing up the child [23]. Nevertheless, children are a factor for escaping loneliness, growing competence, creating joy, vitality in life and reputation for parents. They give social identity to women and link them to the community [24]. Friedman et al. (1994) believe children reduce uncertainty in married life and increase couple’s interdependence [25].

Another influencing factor in childbearing decision is the contrasting pro-nationalistic macro-policies of the country on one hand, and emergence of a new generation of individualistic and secular mentalities among teenagers and youths on the other hand [26]. Solutions for existing population problems as perceived by population policy-makers in Iran are to increase births to prevent aging, government incentive policies to increase fertility, and regional policies to prevent population imbalance [27].

Nevertheless, developing personal and individualistic values in contemporary Iranian society is an inclusive and recognizable fact. Generally, people give priority to their own personal wishes and values rather than giving priority to collective wishes and traditional family values. Moreover, they have freedom, authority and the will against all forces. They are responsible for their own actions, and carry out these actions freely, consciously, and according to their personal decisions [28].

As a result, with individualistic attitude and reconsideration of adolescents and young adults, success of incentive policies for childbearing is doubtful. Abbasi-Shvazi argues that population incentive policies in other countries like Singapore has not led to increased fertility rate. To implement incentive policies, it is necessary to study social and cultural context, people's needs, population priorities, women's and couple's perspectives on lifestyle and number of children [27]. Also, a study by Mahmoodi et al. (2012) showed that no financial incentive scenario can prevent the downward spiral of population growth for at least 14 to 15 years (by 2025) [29].

It is essential that most women's concerns be reviewed and determined in order to explain childbearing process. Researchers' incomplete understanding of the methods in which childbearing decisions are made as well as the factors and concerns that determine such decisions have been revealed in policies and programs discussions that are designed to influence fertility [17]. Furthermore, several events and concerns have received little attention. These are in particular: hesitation to get pregnant or prevent pregnancy, women's mental conditions, concerns related to child health, and women's concerns for childbearing in general [30]. In fact, childbearing decision making and the concerns influencing this decision are affected by social backgrounds and people's 
communication-social networks [31]. Therefore, differences in social and cultural backgrounds affect concerns and process of childbearing decision making.

Studies indicate that no research in Iran has directly examined women's concerns in childbearing decisions. Given the fertility changes in the past three decades in Iran, it is necessary to identify factors that influence women's behaviors, ideals, desires for having children, and to use them as the basis for population policy making. Researchers believe that presently, attitudes and theoretical patterns, and consequently women's, families' reproductive behaviors are evolved in such a way that cannot be easily changed with decisions and views of policy makers and planners [32].

Deeper understanding of women's concerns facilitates the providing of more appropriate and sensitive services about childbearing decision making as well as identifying the determinants of the decision. The results of this research will help midwives and other service providers to realize how to accompany women in this process and provide appropriate strategies and interventions.

\section{Methods}

Given the research question in this study, qualitative approaches were used in seeking to understand human emotions and hidden human meanings of everyday life experiences [33]. Since the study aimed to achieve a deeper understanding of women's concerns about childbearing decision making process, conventional content analysis method was used.

The current study was conducted from October 2012 to July 2013 in Tehran. Purposeful sampling commenced and continued up to data saturation. The participants were primiparous married women or nulliparous married women who used contraceptive methods. None of these women had infertility history and they were able to convey their experiences and willing to participate in the study.

According to the qualitative research method, data collection was performed by unstructured depth-interview at a proper place that participants were satisfied with and felt comfortable. The researcher explained the purpose of the study to the participants and the location of the interview was determined as they desired after receiving their verbal consent to participate in the study. The participants were informed in advance about the possible length of interviews and they were recorded by prior arrangement and consent of the participants.

At first, the interview began with a general question about making a decision on pregnancy or contraception, for instance: "Would you explain to me how you made this decision?", "What made you decide so and act accordingly?” At the next stage, based on given answers and extracted data, probing questions were asked such as "Please elaborate it for me", "Please give a real example so that I can understand it". These were to encourage participants and reach deeper information about them. The interviews took 20 to 120 minutes and the response time was different for each participant.

Interviews continued up to data saturation. In this study, data saturation was achieved in twentieth interview for the researcher and two additional interviews were conducted to ensure that there would be no new data.

Data analysis was performed simultaneously with data collection. Moreover, Lundman and Graneheim method was used for this propose. Five steps have been proposed for qualitative data analysis in this method as follows: 1) Writing out the full interview immediately after each interview, 2) Reading the full interview text to get an overall understanding of the content, 3) Determining meaning units and primary codes, 4) Classifying similar primary codes in more comprehensive categories and 5) Determining the hidden content of data [34].

Also in this study, the audio recordings were transcribed and typed verbatim. They were encoded after carefully reading for several times and immersing in data. First, the meaning units were extracted from interviews. Thereafter, they were encoded. Data were categorized based on comparing differences and similarities after several preliminary interviews. The categories began to develop through adding interviews. To reduce the number of initial categories, they were also merged if possible after comparing them. Each category was labeled such that it indicated its content.

To ensure the accuracy and reliability of the data, four criteria (i.e., credibility, confirmability, dependability and transferability) were used according to Lincoln and Guba [35] [36]. Therefore, it was tried to help in providing data credibility by repeatedly reading interviews, data immersion, long meetings with participants, using participants opinions to confirm the extracted codes and classes, and having maximum variation in samples in terms of age, occupation, education level and financial situation. All interviews and data coding are carried out by the researcher (i.e., Ph.D. student of Reproductive Health). Moreover, the coding and categories are reviewed 
and approved by six University Professors whom are experts in qualitative research studies. Interview contents were reviewed by supervisors and there was a high degree of agreement among the obtained results.

This article is a part of a qualitative study on childbearing decision making process approved by the Ethics Committee of Deputy of Research of Shahid Beheshti University of Medical Sciences. Relevant authorities' approval was obtained prior to study initiation. At the beginning of interviews, participants were informed about the research purpose, interview method, data confidentiality and participants' freedom to join or leave the study and their verbal consent were obtained for participation in the study. The time and place of interviews were also arranged with the participants, such that they had enough time to participate in the interviews by setting their plans.

\section{Results}

In this study, 22 participants of 16 to 38 years old were studied. During the interview, 16 women were primiparous while 6 women were nulliparous and were using contraceptives. The education level ranged from the fifth grade to postgraduate and the time length of their marriage ranged from 7 months to 9 years (Table 1).

Data analysis identified four categories for concerns of most women about childbearing decision making process including fear and concern, uncertainty, hope, and financial security. These four categories identified a general category or common theme titled concern about one's own future or securing child's future as women's main concerns about childbearing decision making (Table 2).

\section{Table 1. Participants' characteristics.}

\begin{tabular}{|c|c|c|c|c|c|c|c|c|c|c|}
\hline 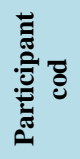 & 茂 & 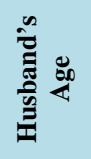 &  & 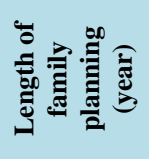 & 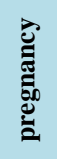 & 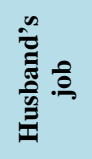 & 势 & 䒿。 & 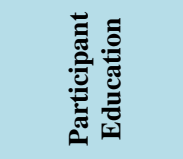 & 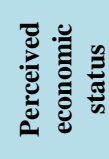 \\
\hline 1 & 16 & 25 & 1.5 & 1 & 1 & SE & Diploma & $\mathrm{Hw}$ & Eight grade & Good \\
\hline 2 & 29 & 28 & 5 & 4.5 & 1 & GE & Undergraduate & $\mathrm{Hw}$ & Eight grade & Average \\
\hline 3 & 28 & 30 & 2 & 2 & 0 & GE & Diploma & $\mathrm{Hw}$ & Diploma & Average \\
\hline 4 & 19 & 25 & 3 & 3 & 0 & SE & Diploma & $\mathrm{Hw}$ & Diploma & Average \\
\hline 5 & 28 & 29 & 1 & 10 month & 1 & SE & Diploma & $\mathrm{Hw}$ & Undergraduate & Low \\
\hline 6 & 20 & 27 & 1 & 7 (month) & 1 & SE & Diploma & $\mathrm{Hw}$ & Diploma & Average \\
\hline 7 & 32 & 35 & 7 & 7 & 1 & SE & Diploma & St & Undergraduate & Average \\
\hline 8 & 29 & 35 & 4.5 & 4 & 1 & SE & Master & St & Undergraduate & Good \\
\hline 9 & 30 & 34 & 3 & 3 & 0 & GE & Undergraduate & $\mathrm{Hw}$ & Diploma & Average \\
\hline 10 & 38 & 32 & 2.5 & 2 & 1 & GE & Fifth grade & $\mathrm{Hw}$ & Fifth grade & Average \\
\hline 11 & 27 & 30 & 1 & 3 (month) & 1 & GE & Diploma & $\mathrm{Hw}$ & Diploma & Low \\
\hline 12 & 27 & 27 & 5.5 & 5 & 0 & GE & Undergraduate & GE & Undergraduate & Average \\
\hline 13 & 28 & 31 & 9 & 8.5 & 1 & GE & Diploma & GE & Undergraduate & Average \\
\hline 14 & 19 & 28 & 7 (month) & 0 & 1 & GE & Undergraduate & $\mathrm{Hw}$ & Diploma & Average \\
\hline 15 & 31 & 31 & 4.5 & 4 & 1 & SE & Diploma & St & Undergraduate & Average \\
\hline 16 & 29 & 29 & 3.5 & 3.5 & 0 & SE & Diploma & GE & Postgraduate & Low \\
\hline 17 & 18 & 28 & 2.5 & 2 & 1 & SE & Diploma & $\mathrm{Hw}$ & Diploma & Good \\
\hline 18 & 27 & 30 & 4 & 3.5 & 1 & SE & Diploma & $\mathrm{Hw}$ & Diploma & Average \\
\hline 19 & 23 & 27 & 2.5 & 2 & 1 & SE & Diploma & $\mathrm{Hw}$ & Diploma & Good \\
\hline 20 & 36 & 43 & 7 (month) & 2 (month) & 1 & SE & Postgraduate & GE & Diploma & Average \\
\hline 21 & 32 & 35 & 7 & 7 & 1 & SE & Diploma & $\mathrm{Hw}$ & Undergraduate & Average \\
\hline 22 & 30 & 32 & 2.5 & 2 & 0 & SE & Undergraduate & GE & Undergraduate & Good \\
\hline
\end{tabular}

Job (SE = self-employed, GE = Government Employee, $\mathrm{St}=$ Student, $\mathrm{Hw}=$ Housewife). 
Table 2. Results from interviews analysis.

\begin{tabular}{|c|c|c|}
\hline Meaning unit & Sub-category & Theme \\
\hline $\begin{array}{l}\text { - Fear of suffering infertility and its stigma } \\
\text { - } \quad \text { Fear of the discord between education/employment and } \\
\text { - } \text { Fear of restriction } \\
\text { - Social phobia } \\
\text { - Skeptical of spouse's accountability } \\
\text { - Skeptical of the continuity of married life } \\
\text { - Skeptical of having child care skills } \\
\text { - } \quad \text { Skeptical of physical and mental readiness } \\
\text { - Hope to solve the economic problems due to better income } \\
\text { - Hope to stabilize family } \\
\text { - Hope to the perfection of life and generation survival } \\
\text { - Hope to develop motivation, enthusiasm and momentum } \\
\text { - } \text { Heavy cost of childbearing and child care } \\
\text { - Necessity of couples' employment to provide cost of living } \\
\text { - Financial aid dependency on the family, the feeling to be a } \\
\text { burden }\end{array}$ & $\begin{array}{l}\text { Fear and concern } \\
\text { (personal distress) }\end{array}$ & $\begin{array}{l}\text { concern about one's own } \\
\text { future situation or securing } \\
\text { child future }\end{array}$ \\
\hline
\end{tabular}

\subsection{Fears and Concerns}

One of the points most frequently repeated by the participants was fear and concern which was proposed in different forms such as fear of suffering infertility and its stigma, fear of the discord between education/employment and childbearing, fear of restriction and social phobia.

One of the most points was fear and concern of suffering infertility and its stigma. In this regard, one participant said: "I'm afraid of deciding to get pregnant but won't be able to; I'm frightened due to the fact that I haven't tried so far to see whether I'm able to get pregnant or not, I'm so scared of this” (participant 22, 30 years old, 2 years of contraception, undergraduate).

Fear of the stigma by the family, relatives and friends was evident in many participants' words. One participant said: "We're treated by others as liars who were sick and only claiming to prevent pregnancy" (participants 10, 38 years old, pregnant, 2 years contraception, fifth grade).

Fear of the discord between education/employment and childbearing was one of the forms of fear that women were exposed to in decision making process. One participant said: "There are two ladies in my workplace who have little kids. They have to take time off regularly, and their names are the first to think of when layoff is considered by the manager. These things really make me too worried to be pregnant." (Participant 12, 27 years old, 5 years of contraception, undergraduate).

Fear of losing good job and education opportunities was felt in the majority of women working and studying. In this regard, one participant said: "I was enjoying good working conditions and excellent salary and benefits. However, I had to take a leave because of my pregnancy and my hard situation, I'm afraid of losing my job (participant 20, 36 years old, pregnant, 2 months of contraception, diploma).

All women reported fear and concern of having their freedom of action and desires limited and somehow being prevented from the desired life after childbearing. Regarding reasonable assessment of cost-benefit, most women believed that having a child was an obstacle to achieving the goals of life including business, financial stability and travel. This assessment would often lead to give other desires higher priority than motherhood. Thus, they are effective factors in delayed childbearing. One of the main concerns of women was the fears of being limited, which have made them to prevent pregnancy and not willing to be pregnant, for example one participant said: "If we had a child, we couldn't travel any time we wanted to. I see parents with children not enjoying their life. I don't think that I'm ready to limit myself by having a kid.” (Participant 16, 29 years old, 3 years of contraception, postgraduate).

Most women described an intense fear of the existing social harms and childbearing in the current social conditions. In this regard, one participant stated:

"When I see so many lies, theft and guiles, etc. in community, how can a child grow up in such a community? 
Even talking about it makes me shiver with fear and I feel stressed. I'm scared that my child would commit a crime." (Participant 22, 30 years old, 2 years of contraception, undergraduate).

\subsection{Skepticism}

Uncertainty was one of the points repeated by the majority of participants and it was stated in different forms such as skeptical of spouse's accountability, skeptical of the continuity of married life, skeptical of having child care skills, skeptical of physical and mental readiness.

In this study, the relationship between couples had a major role. In addition to doubting their motherhood role, women were also uncertain of their partners' fatherhood role and the quality of their relationship with their partners. In most participants, the sense of doubt about continuity of married life was somehow expressed, especially in women who used contraceptive methods. One participant stated:

"We didn't want to have a baby. We tried to get to know each other better. We had lots of rows. I wasn't much sure that my husband could take the fatherhood responsibility. At times, we seriously argued." (Participant 2, 29 years old, pregnant, 5 years of contraception, eighth grade).

Regarding skepticism about physical and mental readiness for childbearing and child care, participants mentioned several points. In this regard, a woman said: "I was always doubtful not to be physically or mentally prepared to be a mother. I always doubted whether I could take care of a baby, this preoccupied my mind for rather a long time" (participant 18, 27 years old, pregnant, 3 years of contraception, diploma). Another participant noted: "We both doubt whether we can raise a child. I think we both lack the required educational skills (participants 12, 27 years old, 5 years of contraception, undergraduate).

\subsection{Hope}

In addition to uncertainty that was the main concern described by the majority of participants, the paradoxical sense of hope was also reported by all of them. The sense originated from hope and trust in God's grace, hope to solve the economic problems due to better income, hope to stabilize family, hope to the perfection of life and generation survival, hope to develop motivation, enthusiasm and momentum after childbearing. Regarding hope due to reliance on God, a participant said: "I'm afraid of the situation of community with so many young people with mental illness, depression and suicide. If it isn't for God's blessing, I don't think anything can protect the child in this situation. It is hope and trusts in God that make me feel calm." (Participant 13, 28 years old, pregnant, 9 years of contraception, associate diploma).

The belief that a child would be bestowed by God was expressed by a participant as follows: "I believe that the kid brings his daily bread with himself and God helps. One won't be left helpless, for example, we sometimes had money problems, but God helped us." (Participant 6, 20 years old, pregnant, 7 months of contraception, diploma).

Hope to solve the economic problems due to increase in provisions after childbearing was expressed by most participants. In this regard, one participant said "Everything will be okay; the kid brings his daily bread with himself. We won't always live like this. Our salary will rise, my husband would get overtime pay, everything will get better" (participant 11, 27 years old, pregnant, 3 months of contraception, diploma).

Most participants, doubting their husbands' accountability, expressed a sense of hope that made their lives more stable. The hope was expressed as a result of childbearing by participants.

"Surely a kid connects us to each other because we gave birth to him or her. I'm not alone anymore; he isn't alone as well. The kid would be a common thing between us which makes our string of life not to break up easily. The shared thing makes one hopeful. I'll be the kid's mother, and he'll be the father of my child, my husband won't be alone anymore" (participant 12, 27 years old, 5 years of contraception, undergraduate).

Hope to develop motivation, enthusiasm and momentum was expressed by most participants which results from the child. In this regard, a participant's quotations will be referred to here.

"I feel one should have something of his own, a motivation and hope to continue living. Something that makes one feels perfect. When you don't have a child, you won't desire for other things, as well (participant 10, 38 years old, pregnant, 2 years of contraception, fifth grade).

\subsection{Financial Security}

Financial security was one of the main concerns expressed by all participants, even by those with high income. 
Financial concerns were described by participants in various forms such as pregnancy and childbirth costs in the current conditions, the high cost of child care and securing child's future, low income, couples with no fixed job and lack of job security, need of employment for couples to provide living costs, financial dependency to the family and the feeling to be a burden. One participant said "One can't afford all of the financial problems of the family; both of us knew that having a baby in these conditions is just a desire which isn't compatible with our real situation" (Participant 16, 29 years old, 3 years of contraception, postgraduate).

Another concern expressed by all participants was economic hardship particularly the lack of housing was considered one of the major issues that they faced. In this regard, one participant noted: " $60 \%-70 \%$ of the issues are related to financial and economic problems, with no peace of mind, oh you're pregnant, and you have a rented residence" (participant 22, 30 years old, 2 years of contraception, undergraduate).

Lack of fixed income and having no job security were the concerns described by many participants. For some participants, financial dependency on the family was one of the economic concerns that hindered economic security and readiness for childbearing. In this regard, one participant said: "My father-in-law helped us; in fact we were dependent on my husband's family. For example, I didn't like to have a kid in that situation and be a burden on them. I always thought we wouldn't have a baby until we're independent" (participant 2, 29 years old, pregnant, 5 years of contraception, eighth grade).

One of the main concerns of the participant was costs of pregnancy, childbirth and child care in the current conditions. One woman explained: "In the first few years, we tried to make our financial situation better to be able to secure the child, for example, being able to pay the costs of pregnancy" (participants 21, 32 years old, pregnant, 7 years of contraception, undergraduate).

Due to the mentioned concerns of participants confronting childbearing decision making and considering all these concerns, it can be concluded that concerns about one's own future or securing child's future are their main worries. In this regard, two quotations from participants are as follows:

"It's not that I don't want to have a kid. I already liked to have one. But I was always worried and scared. I just didn't want him to be sad because of financial situation. I didn't want him to grow up in hardship. He would tell me in future why he was brought to this world at all!" (Participant 10, 38 years old, pregnant, 2 years of contraception, fifth grade).

"We're responsible for the newborn baby, his life, the quality of his life, and his education, as well. In addition, we should have proper conditions in every respect; on the one hand, we're thinking about our success and educational and career promotion, on the other hand, we're thinking about our kid's future." (Participant 16, 29 years old, 3 years of contraception, postgraduate).

\section{Discussion}

This study has addressed the main concern of women for childbearing decision making for the first time in Iran. Based on the participants' views, concerns about one's own future or securing child's future are the most important concerns of women. Interviews provided an opportunity for participants to assess difficult situations, concerns, ambivalences, paradoxes and emotions related to their decision making. In women under study, there was the desire of motherhood and a variety of emotions such as fear, skepticism, hope and wavering similar to what SEVÓN reported in Finland [30].

Fear of suffering infertility and its stigma, fear of losing good job and education opportunities, restriction and social phobia were women's concerns about childbearing decision making. In this study, tendency to avoid possible risk provoked two different reactions in women. Lack of confidence in being a good mother in some women caused hesitation in them to give birth to a child. This was due to the fact that they had not tried it before. In contrast, sometimes simultaneously, the likelihood of age-related infertility made some women feel that they should give birth to a child despite their hesitation before it was too late. This conservative approach toward childbearing is consistent with theories of rational choice, risk aversion and gender equity [37]. In study by Rijkin (2009), concerns about age and losing childbearing opportunities due to reproductive biological clock were proposed by majority of women [38].

The study of Mynarska (2007) in Poland showed that age was a prominent and important concept in reproductive planning [39]. Also the study of Settersten et al. in America showed that age norms are particularly related to the transition periods pertaining to family including marriage, entry into parenting period and the completion of this period [40]. 
Fear of the stigma of being disabled and sick were underlined by women in this study. It seems that childbearing decision making is largely dependent on cultural and normative traditions related to childbearing decision making. There is an exact time for motherhood in cultural tradition [30]. This cultural tradition sets a woman's attitude in such a way that she would choose an appropriate time for motherhood in the permissible proper age. For example, the marital relationship at the appropriate time is of importance after having a permanent job [41]. The concern about the fear of social label was not found in a similar study.

The discord between education/employment promotion and childbearing, and the fear of losing these situations was another concern reported by women in this study. If childbearing decision making is regarded from the prospect of woman's job or work, it would lead to friction, anxiety, doubt or guilt. Balance between work and childbearing is one of the elements developing stress in women's lives [30]. The results of the study of Moony (2009) also revealed that concerns proposed repeatedly by women and affecting their childbearing decision making were that in addition to a very strong desire for childbearing, some other competitive priorities were important for them including job, education, travel, personal achievement and financial security. Fear of losing these priorities created uncertainty in women. In this regard, the study of Armenti (2004) on the academic Canadian women showed how they tried to hide their pregnancy during the job hunt, or time their pregnancy based on the competition calendar to take over the positions [42].

One of the main concerns of women in this study was that their individual and social freedom would be limited by childbearing. The study of Rijken (2009) in the Netherlands showed that limited freedom was a very important issue in childbearing decision making. In the Netherlands Fertility and Family Survey, 50\% of men and women who had not any child up to 30 years old (women) or 33 years old (men) mentioned that the desire to enjoy their freedom was the main reason for delaying childbearing [38].

One of the new findings of this study which have not been reported in similar studies is social phobia and fear of social harms. In other words, lack of social security and fear of the threatened future for the child are of main concerns of women about childbearing decision making process.

Also uncertainty is another finding in this study. Women were uncertain about maturity and readiness for motherhood and that both partners were ready for playing parenting role or not. One aspect of the natural life for most women is having a good relationship with a spouse. Women interviewed in this study expressed concerns about the continuity of married life. It seems that the relationship between two partners affect the formation of reproductive decisions [43] and reports related to reproductive behavior emphasize the importance of the interaction between spouses at the time of childbearing decision making [44] [45]. Also, Pezeshki et al. (2005) suggested on the basis of their study that couple may have children in order to strenghten the marital relationship [13].

Along with doubt, the paradoxical sense of hope was also reported by women. Hope and trust in God's grace, hope to solve the economic problems due to increased salary are among the interesting findings of this study. Studies have shown that fertility rate is changed in many communities according to the intensity of religious beliefs [46]. Couples with similar educational backgrounds or similar cultural or religious beliefs tend to take similar decisions related to reproduction [47]. Hyun Yoo (2012) believes that beliefs and personal experiences related to childbearing, sexual experience, and the social environment may also affect the ambivalent approach. The people with strong pronatalist beliefs might be glad of pregnancy, even if they do not feel the current stage of life is the best time for childbearing [48].

The dubious feeling of having a baby due to the uncertainty about the marital relationship stability in contrast to the hope felt for having stronger relationships as a result of childbearing was reported by women in this study. The study of Rijken showed that understanding the relationship quality can affect couple's childbearing decision making [49]. People who have a good marital relationship, but not ideal enough, may decide to restore their relationship with childbearing. On the other hand, the women who feel very happy with their husband may fear about the negative effect of childbearing on their relationships. Some studies show the negative effect of childbearing on marital relationship quality [50]. Based on Friedman's, value of children, reinforcing family strength and reducing doubts are important factors influencing fertility decision making [51].

Economic problems were one of the main concerns of women in this study. The study by Peterson showed that providing economic stability and security, the social norm of marriage at old age and educational purposes are considered to be the main concerns for delayed childbearing decision making [52]. In several studies housing, economic insecurity, especially unemployment [53] and the lack of family support systems have been introduced as main factors for delayed childbearing decision making [54]-[56]. Also the study by Fokkema and Lief- 
broer showed that women with higher education delay childbearing in countries where it was difficult to reconcile work and family life [57]. However, education had a positive effect on birth rate if there was a good compatibility between work and family life. They also concluded that childbearing was more likely for unemployed women in a country with high level of economic security [47].

\section{Summary}

The overall result of this study shows that there is a paradox of women decision making which is related to the struggle between women's doubts and hopes. Also, the contrast of a strong sense and desire to be a mother against the fear of limitations, economic concerns and the attempt to improve her own future versus securing child's future and the rational choice in this regard.

This study was limited to the first pregnancy because it seems that the nature of decision making and existing concerns in this process are different for the first, second and the subsequent children. However, the decisions of younger and older parents for next children may be interestingly different from the past; the differences are expected to be higher in the first decision to have a child. Childbearing decision making is a decision to be made jointly by the couple. The target group in this study was only women because women have more information in this area and are the final decision makers in the process. For a more comprehensive understanding of the childbearing decision making process, authors suggest the study of couple's concerns.

In qualitative studies, findings largely depend on the social and cultural context of data. Sampling with a maximum variation at different ages and different levels of economic and social levels are considered to be the strong points of this study. There are limited and often retrospective studies in regard to childbearing decision making concerns. In addition, participants in the above mentioned studies were interviewed long after giving birth to their baby, while the women interviewed in this study were in pregnancy period or had prevented the pregnancy.

Finally, the country health authorities would acquire deep data in the field of most women's concerns about childbearing decision making and would use the results of this research for appropriate interventions. Other researchers can also design interventional studies based on the findings of this study.

\section{Acknowledgements}

This article is taken from the $\mathrm{PhD}$ thesis of Reproductive Health in Shahid Beheshti University of Medical Sciences. Hereby, we appreciate the cooperation of Research Deputy of the university and Nursing \& Midwifery Faculty at Shahid Beheshti University and all participants in the study who gave us their precious time.

\section{References}

[1] Aghajanian, A. and Mehryar, A. (1999) Fertility Transition in the Islamic Republic of Iran: 1976-1996. Asia-Pacific Population Journal, 14, 21-42.

[2] Abbasi-Shavazi, M.J., McDonald, P. and Hosseini-Chavoshi, M. (2009) The Fertility Transition in Iran: Revolution and Reproduction. Springer Publisher, 67-80. http://dx.doi.org/10.1007/978-90-481-3198-3

[3] Simbar, M. (2012) Achievements of the Iranian Family Planning Programmes 1956-2006. EMHJ, 18, 279-286.

[4] Haddad, G.K. and Ghanbarabadi, M.B. (2011) Analysis of Rural and Urban Women's Participation in Work Market Using Parametric and Nonparametric Econometrics Methods. Economical Research, 45, 151-174.

[5] Erfani, A. (2012) The Impact of Family Planning on Women's Educational Advancement in Tehran, Iran. ICRW-FE. http://www.icrw.org/files/publications/Erfani\%20MS\%20edit\%20Feb\%202013.pdf

[6] Erfani, A. (2010) Tehran Survey of Fertility, 2009. A Study on the Reproductive Behavior of Married Women in Tehran: Trends, Correlates, \& Policy Challenges, in Department of Sociology. Nipissing University, North Bay, 8.

[7] Erfani, A. (2013) A Reversal in the Population Policy of Iran: Do Curbin Family Planning Programs Raise Low Fertility? ICRW, Busan, 1-4. http://www.iussp.org/sites/default/files/event_call_for_papers/Erfani.\%20Extended\%20Abstract.\%20\%202013\%20IU SSP_0.pdf

[8] Sobotka, T., Skirbekk, V. and Philipov, D. (2011) Economic Recession and Fertility in the Developed World. A Literature Review. Population and Development Review, 37, 267-306. http://dx.doi.org/10.1111/j.1728-4457.2011.00411.x

[9] Carmichael, S. (2011) Marriage and Power: Age at First Marriage and Spousal Age Gap in Lesser Developed Countries. The History of the Family, 16, 416-436. http://dx.doi.org/10.1016/j.hisfam.2011.08.002 
[10] Hughes, M. (2011) Reliability and Dependability in Usability Testing. http://www.uxmatters.com/mt/archives/2011/06/reliability-and-dependability-in-usability-testing.php

[11] Testa, M.R. (2012) The Socio-Economic Determinants of Childbearing Intentions: A Macro-Micro Analysis. In the European Population Conference.

[12] Cooke, A., Mills, T.A. and Lavender, T. (2012) Advanced Maternal Age: Delayed Childbearing Is Rarely a Conscious Choice: A Qualitative Study of Women's Views and Experiences. International Journal of Nursing Studies, 49, 30-39. http://dx.doi.org/10.1016/j.ijnurstu.2011.07.013

[13] Pezeshki, M., Zeighami, B. and Miller, W. (2005) Measuring the Childbearing Motivation of Couples Referred to the Shiraz Health Center for Premarital Examinations. Journal of Biosocial Science, 37, 37-53. http://dx.doi.org/10.1017/S0021932003006485

[14] Yucesahin, M. (2013) Demographic and Human Capital Heterogeneity in Selected Provinces of Turkey: A Scenario Analysis Using the Multi-Dimensional Population Projection Model. IIASA Interim Report IR-13-009 (07 13). IIASA Interim Report IR-13-009. http://www.iiasa.ac.at/publication/more_IR-13-009.php

[15] Razeghi-Nasrabad, H. (2013) Trend and Patterns of Childlessness in Iran. In XXVII International Population Conference of the IUSSP 26-31, Busan.

[16] Nojomi, M. (2010) Delayed Childbearing: Pregnancy and Maternal Outcomes. Iranian Journal of Reproductive Medicine, 8, 80-85.

[17] Nicholas-Mascie-Taylor, C. and Rosetta, L. (2011) Reproduction and Adaptation, Topics in Human Reproductive Ecology, Chapter 13, Understanding Reproductive Decisions. A Hinde. Cambridge University Press, UK.

[18] Rondinelli, C., Aassve, A. and Billar, F.C. (2010) Women's Wages and Childbearing Decisions: Evidence from Italy. Demographic Research, 22, 549-578. http://dx.doi.org/10.4054/DemRes.2010.22.19

[19] Fisher, K. (2006) Birth Control, Sex and Marriage in Britain. Oxford University Press, Oxford.

[20] Johnson, J. and Tough, S. (2012) Delayed Child-Bearing. Journal of Obstetrics and Gynaecology Canada, 34, 80-93.

[21] Tough, S., Tofflemire, K., Fraser-Lee, N. and Newburn-Cook, C. (2013) Factors Influencing Childbearing Decisions and Knowledge of Perinatal Risks among Canadian Men and Women. Maternal and Child Health Journal, 11, 189198. http://dx.doi.org/10.1007/s10995-006-0156-1

[22] Aghajanian, A. (1988) The Value of Children in Rural and Urban Iran. Journal of Comparative Family Studies, 19, 8597.

[23] Mahmoodian, H. and Poorrahim, M. (2002) Children's Value and Its Relationship with Fertility from Young Couple’s Perspective (Case Study in Behshahr). Population Quarterly Journal, 41, 89-103.

[24] Hoffman, L. and Hoffman, M. (1973) The Value of Children to Parents. In: Fawcett, J.T., Ed., Psychological Perspectives on Population, Basic Books, New York, 19-79.

[25] Friedman, D., Hechter, M. and Kanazawa, S. (1994) A Theory of the Value of Children. Demography, 31, 375-401. http://dx.doi.org/10.2307/2061749

[26] Fazelie, N. (2012) Culture and City: Cultural Transformation in Urban Dialog with Emphasis on Studies in Tehran. Tisa Publication, Tehran.

[27] Abbasi-Shavazi, M. (2013) Population Challenges and Persuasive Policies in Iran. Academia of Medical Sciences, Tehran University.

[28] Naghadan, M. (1997) Key Concepts of Sociology. AvayeNoor Publication, Tehran.

[29] Mahmoudi, M., Kazemiour, S., Ahrari, M. and Nikoonesbati, A. (2013) Predicting Iran's Population Growth Considering Socioeconomic Variables: A Multidisciplinary Approach. Planning and Budget Quarterly, 17, 97-126.

[30] Sevón, E. (2005) Timing Motherhood: Experiencing and Narrating the Choice to Become a Mother. Feminism \& Psychology, 15, 4461-4482.

[31] Murphy, D. and Longo, D. (2009) Encyclopedia of Psychology of Decision Making. Nova Science Publishers, Inc., New York, 1253 p.

[32] Abbasi-Shavazi, M., McDonald, P., Hosseini-Chavoshi, M. and Kavefirouz, Z. (2002) Women’s Attitude toward Fertility Behaviors in Yazd Province: A Qualitative Study. Journal of Social Sciences, 20, 169-203.

[33] Morse, M. and Field, A. (1995) Qualitative Research Methods for Health Professionals. Sage Publications, Thousand Oaks.

[34] Graneheim, U. and Lundman, B. (2004) Qualitative Content Analysis in Nursing Research: Concepts, Procedures and Measures to Achieve Trustworthiness. Nurse Education Today, 24, 105-112. http://dx.doi.org/10.1016/j.nedt.2003.10.001

[35] Lincoln, Y. and Guba, E. (1985) Naturalistic Inquiry. Sage, Beverly Hills. 
[36] Streubert, H. and Carpenter, D. (2007) Qualitative Research in Nursing: Advancing the Humanistic Imperative. Lippincott Williams \& Wilkins, Philadelphia.

[37] Mooney, R. (2009) A Study of Conviction: Desires and Doubts about Having Children. http://hdl.handle.net/1959.13/919883

[38] Rijken, A. and Knijn, T. (2009) Couples’ Decisions to Have a First Child: Comparing Pathways to Early and Late Parenthood. Demographic Research, 21, 765-802. http://dx.doi.org/10.4054/DemRes.2009.21.26

[39] Mynarska, M. (2006) Economic Constrains and Individual Fertility Choices. An Example from Poland. European Population Conference, Liverpool, 22-24 June 2006.

[40] Settersten, R. (1997) The Salience of Age in the Life Course. Human Development, 40, 257-281. http://dx.doi.org/10.1159/000278730

[41] Woollett, A. and Boyle, M. (2000) Reproduction, Women's Lives and Subjectivities. Feminism \& Psychology, 10, 307-311. http://dx.doi.org/10.1177/0959353500010003001

[42] Armenti, C. (2004) May Babies and Posttenure Babies: Maternal Decisions of Women Professors. Review of Higher Education, 27, 211-231. http://dx.doi.org/10.1353/rhe.2003.0046

[43] Zabin, L., Huggins, G., Emerson, M. and Cullins, V. (2000) Partner Effects on a Woman’s Intention to Conceive: "Not with This Partner”. Family Planning Perspectives, 32, 39-45. http://dx.doi.org/10.2307/2648147

[44] Schmidt, L., Sobotka, T., Bentzen, J. and Nyboe-Andersen, A. (2012) Demographic and Medical Consequences of the Postponement of Parenthood. Human Reproduction Update, 18, 29-43.

[45] Beckman, L., Aizenberg, R., Forsythe, A. and Day, T. (1983) A Theoretical Analysis of Antecedents of Young Couples’ Fertility Decision and Outcomes. Demography, 20, 519-533. http://dx.doi.org/10.2307/2061117

[46] Adsera, A. (2006) An Economic Analysis of the Gap Between Desired and Actual Fertility: The Case of Spain. Review of Economics of the Household, 4, 75-95. http://dx.doi.org/10.1007/s11150-005-6698-y

[47] Philipov, D., Othévenon, J., Klobas, L., Bernardi and Liefbroer, A. (2010) Reproductive Decision-Making in a Macro-Micro Perspective (REPRO): Synthesis and Policy Implications. http://www.oeaw.ac.at/vid/download/edrp_1_11.pdf

[48] Hyun-Yoo, S., Hayford, S. and Guzzo, K. (2012) Ambivalence towards Pregnancy: Is It a Singular or Multifaceted Concept? Working Paper Series, Bowling Green State University, The Center for Family and Demographic Research, 1-28. http://www.bgsu.edu/organizations/cfdr

[49] Rijken, A.J. (2009) Happy Families, High Fertility? Childbearing Choices in the Context of Family and Partner Relationships. Dissertation Utrecht University, The Netherlands.

[50] Carmichael, G.A. and Whittaker, A. (2007) Choice and Circumstance: Qualitative Insights into Contemporary Childlessness in Australia. European Journal of Population/Revue Européenne de Démographie, 23, 111-143. http://dx.doi.org/10.1007/s10680-006-9112-4

[51] Friedman, D., Hechter, M. and Kanazawa, S. (1994) A Theory of the Value of Children. Demography, 31, $375-401$. http://dx.doi.org/10.2307/2061749

[52] Peterson, B., Pirritano, M., Tucker, L. and Lampic, C. (2012) Attitudes among American Male and Female Undergraduate University Students. Human Reproduction Update, 27, 1375-1382.

[53] Adserà, A. (2004) Changing Fertility Rates in Developed Countries. The Impact of Labor Market Institutions. Journal of Population Economics, 17, 17-43. http://dx.doi.org/10.1007/s00148-003-0166-X

[54] Mills, M., Rindfuss, R., McDonald, P. and Te-Velde, E. (2011) Why Do People Postpone Parenthood? Reasons and Social Policy Incentives. Human Reproduction Update, 17, 848-860.

[55] Rindfuss, R. and Brauner-Otto, S. (2008) Institutions and the Transition to Adulthood: Implications for Fertility Tempo in Low-Fertility Settings. Vienna Yearbook of Population Research, 2008, 57-87. http://dx.doi.org/10.1553/populationyearbook2008s57

[56] Kreyenfeld, M. (2010) Uncertainties in Female Employment Careers and the Postponement of Parenthood in Germany. European Sociological Review, 26, 351-366. http://dx.doi.org/10.1093/esr/jcp026

[57] Fokkema, T. and Esveldt, I. (2008) Motivation to Have Children in Europe, in People, Population Change and Policies. Springer, Berlin, 141-155. 